\title{
ANALISIS KESTABILAN MODEL MATEMATIKA PENYEBARAN PENYAKIT SIFILIS PADA MANUSIA
}

\author{
N. Muliyani1 ${ }^{1}$ R. Ratianingsih², dan N. Nacong ${ }^{3}$ \\ 1Program Studi Matematika Jurusan Matematika FMIPA Universitas Tadulako \\ Jalan Soekarno-Hatta Km. 09 Tondo, Palu 94118, Indonesia. \\ 1nini01010145@gmail.com, 2ratianingsih@yahoo.com, 3nasrianacong@gmail.com
}

\begin{abstract}
Syphilis is a sexually transmitted infection caused by the bacterium Treponema pallidum spiroset subspecies pallidum. Transmitted through sexual contact, the infection can also be transfered from mother to fetus during pregnancy or at birth, that causes congenital syphilis. The mathematical model that represents the spread of the disease was adapted from a mathematical model SEI. The model classifiles human population into vulnerable suscepted $(S)$ women and men, Exposed $(E)$, and Infected $(I)$, sub-populations of women vulnerable $\left(S_{p}\right)$, subpopulations women incubation period $\left(E_{p}\right)$, sub-populations of women infected $\left(I_{P}\right)$ and a sub-population of men vulnerable $\left(S_{L}\right)$, sub-populations incubation period male $\left(E_{L}\right)$, sub-populations laki- infected men $\left(I_{L}\right)$ considered in the model. The derived models gives two critical point that is free disease and endemic critical point. The existence of a critical point $T_{2}$ must satisfye $A>\mu$ and $B>\mu$. The model was analyzed by the linierized method and Routh-Hurwitz criteria to determine the system stability. The simulation shows that, in case of free-disease syphilis spread condition, the population of women and men has increased. The growth of women population is higher than the men population. it means that the spread of syphilis occurs faster in the men sub-population. In endemic condition of syphilis disease spread, the women population will growth rapidly than the men population.
\end{abstract}

Keywords : : Disease Syphilis, Linearization, SEI Model, Routh-Hurwitz Criterion

\section{ABSTRAK}

Sifilis adalah infeksi menular seksual yang disebabkan oleh bakteri spiroset Treponema pallidum sub-spesies pallidum. Penularannya melalui kontak seksual, infeksi ini juga dapat ditularkan dari ibu ke janin selama kehamilan atau saat kelahiran, yang menyebabkan terjadinya sifilis kongenital. Model matematika yang merepresentasikan penyebaran penyakit tersebut diadaptasi dari model matematika SEI yang mengelompokkan subpopulasi perempuan dan laki-laki rentan Susceptible $(S)$, Exposed $(E)$, dan Infected $(I)$, sub populasi perempuan rentan $\left(S_{p}\right)$, sub populasi masa inkubasi perempuan $\left(E_{p}\right)$, sub populasi perempuan yang terinfeksi $\left(I_{p}\right)$ dan sub populasi laki-laki rentan $\left(S_{L}\right)$, sub populasi masa inkubasi laki-laki $\left(E_{L}\right)$, sub populasi laki-laki yang terinfeksi $\left(I_{L}\right)$ diperhatikan dalam model tersebut. Dari model tersebut diperoleh dua titik kritis yaitu bebas penyakit dan titik kritis endemik. Syarat eksistensi titik kritis $T_{2}$ terpenuhi bila $A>\mu$ dan $B>\mu$. Model yang dibangun selanjutnya dianalisis kestabilannya dengan metode linierisasi dan Kriteria Routh-Hurwitz. Hasil simulasi penyebaran penyakit sifilis menunjukkan bahwa pada kondisi bebas penyakit, populasi perempuan dan laki-laki mengalami peningkatan, dimana peningkatan jumlah populasi perempuan lebih tinggi dibanding populasi 
laki-laki. Hal ini menunjukkan penyebaran penyakit sifilis lebih cepat terjadi pada kelompok populasi laki-laki. Sebaliknya hasil simulasi keadaan endemik memperlihatkan bahwa penyebaran penyakit sifilis lebih cepat pada populasi perempuan.

Kata Kunci : Kriteria Routh-Hurwitz, Linierisasi, Model SEI, Penyakit Sifilis

\section{PENDAHULUAN}

Secara umum ada dua jenis penyakit, yaitu penyakit menular dan tidak menular. Kelompok penyakit menular ada yang ringan dan ada yang berat, yang ringan misalnya influenza dan diare.Sedangkan yang berat seperti sifilis, polio, demam berdarah, campak, flu burung, HIVIAIDS dan sederet penyakit lainnya.Menular tidaknya suatu penyakit harus tetap diwaspadai dan tidak boleh dianggap remeh, karena ketika seseorang terkena suatu penyakit, aktivitas kehidupannya akan terganggu. Apalagi jika penyakitnya sudah parah, dan menyebabkan kematian (Rafiqah, 2014).

Penyakit sifilis merupakan salah satu penyakit fatal yang disebabkan oleh bakteri spiroclete treponema pallidum subspesies pallidum yang dapat disebarkan atau ditularkan melalui kontak langsung dengan penderita. Tubuh mempunyai kemampuan untuk mengatasi sampai batas tertentu. Dalam hal ini dikatakan bahwa sistem pertahanan tubuh (sistem imun) manusia cukup baik untuk mengatasi dan mengalahkan kuman-kuman penyakit. Tetapi pada penyakit sifilis sistem pertahanan tubuh lemah tidak mampu mencegah kuman atau bakteri itu berkembang biak, sehingga dapat mengakibatkan penyakit semakin parah yang membawa pada kecacatan bahkan kematian(Ardiansyah,2014).

\section{METODE PENELITIAN}

Pada penelitian ini dilakukan dengan membangun model matematika penyebaran penyakit sifilis, kemudian menentukan titik kritis dan menganalisis kestabilan model penyakit sifilis menggunakan matriks Jacobi dan kriteria Routh-Hurwitz. Selanjutnya dilakukan simulasi untuk melihat penyebaran penyakit sifilis pada manusia.

\section{HASIL DAN PEMBAHASAN}

\subsection{Hasil}

\subsubsection{Model Matematika Untuk Penyebaran Penyakit Sifilis}

Penelitian ini merupakan tinjauan matematis terhadap penanganan penyebaran penyakit sifilis pada manusia melalui analisa kestabilandi titik kritis sistem. Tinjauan tersebut meliputi pembuatan suatu model yang dibagi berdasarkan skema penyebaran penyakit sifilis. Skema tersebut dinyatakan dalam suatu diagram kompartemen pada Gambar 1. 


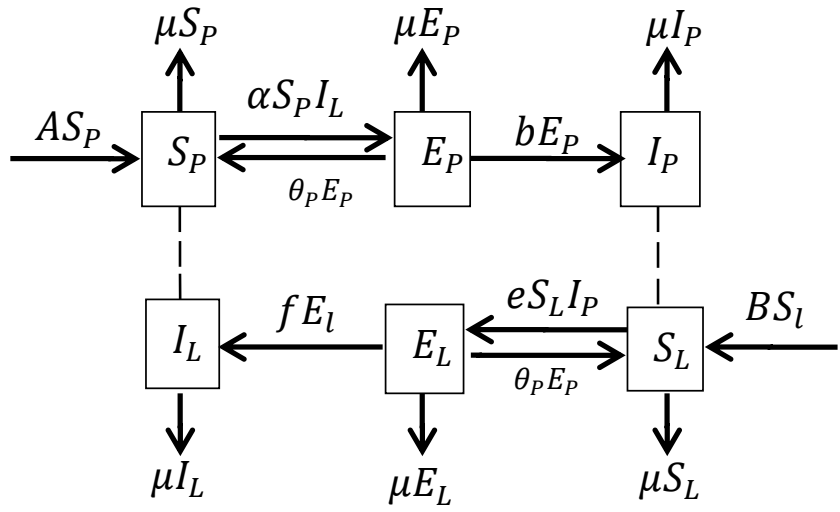

Gambar 1 : Diagram Kompartemen Penyebaran Penyakit Sifilis

Berdasarkan alur perpindahan dalam diagram kompartemen tersebut, modelmatematika penyebaran penyakit sifilisdituliskan ke dalam sistem persamaan differensial (SPD) sebagai berikut:

$\frac{d S_{p}}{d t}=A S_{p}-\mu S_{p}-\alpha S_{p} I_{L}+\theta_{p} E_{p}$

$\frac{d E_{p}}{d t}=\alpha S_{p} I_{L}-\mu E_{p}-b E_{p}-\theta_{p} E_{p}$

$\frac{d I_{p}}{d t}=b E_{p}-\mu I_{p}$

$\frac{d S_{L}}{d t}=B S_{L}-\mu S_{L}-e S_{L} I_{P}+\theta_{L} E_{L}$

$\frac{d E_{L}}{d t}=e S_{L} I_{P}-\mu E_{L}-f E_{L}-\theta_{L} E_{L}$

$\frac{d I_{L}}{d t}=f E_{L}-\mu I_{L}$

\subsubsection{Menentukan Titik Kritis}

Titik kritis yang dihasilkan dari persamaan (1), (2), (3), (4), (5) dan (6) diperoleh titik kritis bebas penyakit $\left(T_{1}\right)=(0,0,0,0,0,0)$. Titik kritis bebas penyakit yang demikian menunjukkan bahwa penyakit sifilis akan membuat seluruh kelompok populasi terinfeksi dan akhirnya mati. Dari persamaan (1), (2), (3), (4), (5) dan (6) diperoleh juga titik kritis endemik $T_{2}=\left(S_{p}, E_{p}, I_{p}, S_{L}, E_{L}, I_{L}\right)$ yang memenuhi

$$
\begin{aligned}
& S_{P}=\frac{(\mu+b)(-\mu+B) \mu\left(\mu+f+\theta_{L}\right)}{e b(f+\mu)(A-\mu)} \\
& E_{P}=\frac{\mu\left(f+\mu+\theta_{L}\right)(-\mu+B)}{b e(\mu+f)}
\end{aligned}
$$




$$
\begin{aligned}
& I_{P}=\frac{\left(f+\mu+\theta_{L}\right)(-\mu+B)}{e(\mu+f)} \\
& S_{L}=\frac{(f+\mu)\left(\theta_{P}+\mu+b\right)(A-\mu) \mu}{f \alpha(\mu+b)(-\mu+B)} \\
& E_{L}=\frac{\mu\left(\theta_{P}+\mu+b\right)(A-\mu)}{f \alpha(\mu+b)} \\
& I_{L}=\frac{\left(\theta_{P}+\mu+b\right)(A-\mu)}{\alpha(\mu+b)}
\end{aligned}
$$

\subsubsection{Kestabilan Titik Kritis}

Titik kritis bebas penyakit $\left(T_{1}\right)=(0,0,0,0,0,0)$ dikaji analisa kestabilan di titik kritis dengan menggunakan matriks Jacobi, dari sistem persamaan selanjutnya dievaluasi di titik $(0,0,0,0,0,0,0)$

Nilai eigen $J_{1}$ diperoleh dari det $\left(J_{1}-\lambda I\right)=0$

$$
J_{1}=\left[\begin{array}{cccccc}
A-\mu-\lambda & \theta_{p} & 0 & 0 & 0 & 0 \\
0 & -\mu-\mathrm{b}-\theta_{p}-\lambda & 0 & 0 & 0 & 0 \\
0 & \mathrm{~b} & -\mu-\lambda & 0 & 0 & 0 \\
0 & 0 & 0 & B-\mu-\lambda & \theta_{L} & 0 \\
0 & 0 & 0 & 0 & -\mu-f-\theta_{L}-\lambda & 0 \\
0 & 0 & 0 & 0 & f & -\mu-\lambda
\end{array}\right]
$$

sehingga menghasilkan nilai-nilai eigen sebagai berikut :

$\lambda_{1}=\left(-\mu-\mathrm{b}-\theta_{p}\right), \lambda_{2}=A-\mu, \lambda_{3}=-\mu, \lambda_{4}=-\mu, \lambda_{5}=-\mu-f-\theta_{L}, \lambda_{6}=B-\mu$

Hasil tersebut memberikan syaratkestabilan dimana nilai eigen harus bernilai negatif bagi $\lambda_{2}$ dan $\lambda_{6}$ yaitu $\mu<A$ dan $\mu<B$. Kedua syarat tersebut menjadikan seluruh nilai eigen bernilai negatif, sehingga disimpulkan $T_{1}$ adalah stabil dengan syarat tersebut.

Kestabilan titik kritis endemik terlebih dahulu dianalisa dengan melakukan transformasi terhadap variabel $(R, S, T, U, V, W)$.Sehingga nilai eigen diperoleh dari persamaan karakteristik yang didapat dinyatakan dalam

$$
a_{0} \lambda^{6}+a_{1} \lambda^{5}+a_{2} \lambda^{4}+a_{3} \lambda^{3}+a_{4} \lambda^{2}+a_{5} \lambda+a_{6}=0
$$

dengan

$a_{0}=1$

$a_{1}=\frac{\left(\begin{array}{l}4 \mu^{3}(5 f+5 b) \mu^{2}+\left(b^{2}+(\theta p+6 f) b+A \theta p+\theta L f+\theta L b+f^{2}\right) \mu \\ +f b^{2}+\left(f^{2}+(\theta L+\theta p) f+\theta L B\right) b+A \theta p f\end{array}\right)}{(f+\mu)(\mu+b)}$ 


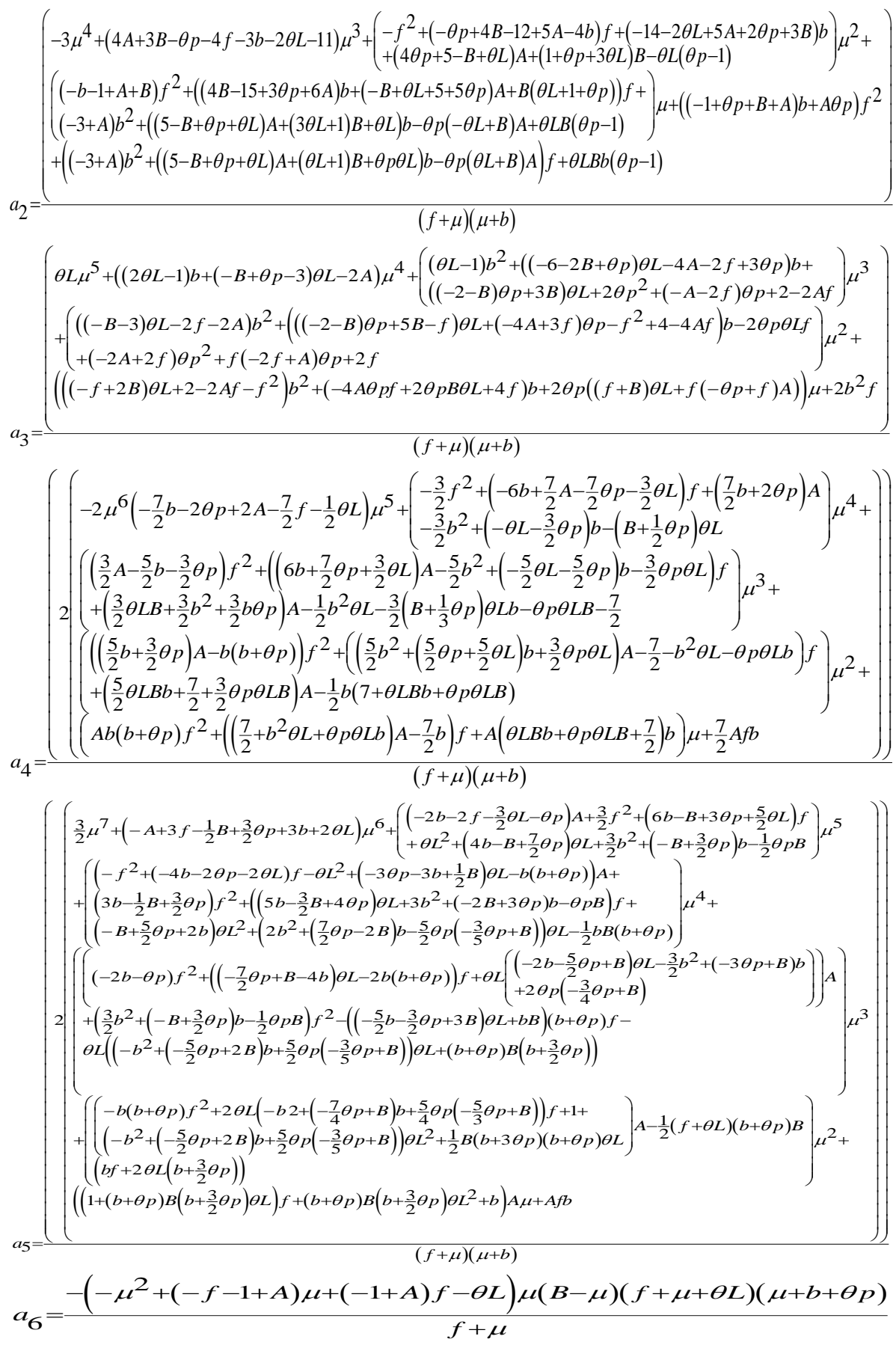

Persamaan (7) dinyatakan dalam Tabel 1 Routh Hurwitz dimana hanya satu baris teratas yang ditentukan langsung dari persamaan karakteristiknya sebagai pada Tabel 1. 
Tabel 1 : Routh Hurwitz

\begin{tabular}{|c|c|c|c|c|}
\hline$\lambda^{6}$ & $a_{0}$ & $a_{2}$ & $a_{4}$ & $a_{6}$ \\
\hline$\lambda^{5}$ & $a_{1}$ & $a_{3}$ & $a_{5}$ & 0 \\
\hline$\lambda^{4}$ & $b_{1}$ & $b_{2}$ & $b_{3}$ & 0 \\
\hline$\lambda^{3}$ & $c_{1}$ & $c_{2}$ & 0 & 0 \\
\hline$\lambda^{2}$ & $d_{1}$ & $d_{2}$ & 0 & 0 \\
\hline$\lambda^{1}$ & $e_{1}$ & 0 & 0 & 0 \\
\hline$\lambda^{0}$ & $f_{1}$ & 0 & 0 & 0 \\
\hline
\end{tabular}

Dari Tabel 1 diperoleh nilai sebagai berikut :

$$
\begin{aligned}
& b_{1}=\frac{a_{1} a_{2}-a_{0} a_{3}}{a_{1}}=\frac{\left(\frac{A}{N}\right)\left(\frac{B}{N}\right)-(1)\left(\frac{C}{N}\right)}{\left(\frac{A}{N}\right)}=\frac{A B-C N}{A N} \\
& b_{2}=\frac{a_{1} a_{4}-a_{0} a_{5}}{a_{1}}=\frac{\left(\frac{A}{N}\right)\left(\frac{D}{N}\right)-(1)\left(\frac{E}{N}\right)}{\left(\frac{A}{N}\right)}=\frac{A D-E N}{A N} \\
& b_{3}=\frac{a_{1} a_{6}-a_{0} 0}{a_{1}}=a_{6}=\frac{F}{M} \\
& c_{1}=\frac{b_{1} a_{3}-a_{1} b_{2}}{b_{1}}=\frac{\left(\frac{A B-C N}{A N}\right)\left(\frac{C}{N}\right)-\left(\frac{A}{N}\right)\left(\frac{A D-E N}{A N}\right)}{\left(\frac{A B-C N}{A N}\right)}=\frac{C A B-C C N-A A D-A E N}{A N B-C N^{2}} \\
& c_{2}=\frac{b_{1} a_{5}-a_{1} b_{3}}{b_{1}}=\frac{\left(\frac{A B-C N}{A N}\right)\left(\frac{E}{N}\right)-\left(\frac{A}{N}\right)\left(\frac{F}{M}\right)}{\left(\frac{A B-C N}{A N}\right)}=\frac{(A B-C N) E M-A F A N}{(A B-C N) N M} \\
& d_{1}=\frac{c_{1} b_{2}-b_{1} c_{2}}{c_{1}}=\frac{\left(\frac{C A B-C C N-A A D-A E N}{A N B-C N^{2}}\right)\left(\frac{A D-E N}{A N}\right)-\left(\frac{A B-C N}{A N}\right)\left(\frac{(A B-C N) E M-A F A N}{(A B-C N) N M}\right)}{\left(\frac{C A B-C C N-A A D-A E N}{A N B-C N^{2}}\right)} \\
& d_{1}=\frac{\left(\begin{array}{c}
(-A B E M+C N E M+A F A N) C N^{3}+\left(\begin{array}{c}
(-C A B+C C N+A A D+A E N)(A D-E N) M+A B \\
(A B E M-C N E M-A F A N)
\end{array}\right) C N^{2} \\
N A B(A B E M-C N E M-A F A N) C N-(-C A B+C C N+A A D+A E N)(A D-E N) A B N M-A B N A B(A B E M-C N E M-A F A N)
\end{array}\right)}{A N\left(-A B N M+C N^{2} M\right)-(-C A B+C C N+A A D+A E N)} \\
& d_{2}=\frac{c_{1} b_{3}-b_{1} 0}{c_{1}}=b_{3}=a_{6}=\frac{F}{M} \\
& e_{1}=\frac{d_{1} c_{2}-c_{1} d_{2}}{d_{1}}=
\end{aligned}
$$

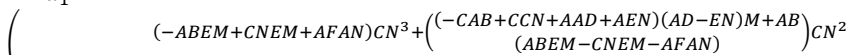

$$
\begin{aligned}
& (-N A B(A B E M-C N E M-A F A N) C N-(-C A B+C C N+A A D+A E N)(A D-E N) A B N M-A B N A B(A B E M-C N E M-A F A N) \\
& A N\left(-A B N M+C N^{2} M\right)-(-C A B+C C N+A A D+A E N) \\
& e_{1}=\frac{\left(\frac{(A B-C N) E M-A F A N}{(A B-C N) N M}\right)-\left(\frac{C A B-C C N-A A D-A E N}{A N B-C N^{2}}\right)\left(\frac{F}{M}\right)}{\frac{\left(\begin{array}{c}
(-A B E M+C N E M+A F A N) C N^{3}+\left(\begin{array}{c}
(-C A B+C C N+A A D+A E N)(A D-E N) M+A B \\
(A B E M-C N E M-A F A N)
\end{array}\right) C N^{2} \\
N A B(A B E M-C N E M-A F A N) C N-(-C A B+C C N+A A D+A E N)(A D-E N) A B N M-A B N A B(A B E M-C N E M-A F A N)
\end{array}\right)}{A N\left(-A B N M+C N^{2} M\right)-(-C A B+C C N+A A D+A E N)}} \\
& f_{1}=\frac{e_{1} d_{2}-d_{1} 0}{e_{1}}=d_{2}=b_{3}=a_{6}=\frac{F}{M}
\end{aligned}
$$

Syarat kestabilan Routh Hurwitz mengatakan bahwa banyaknya akar tak stabil sama dengan banyaknya perubahan tanda pada kolom pertama Tabel Routh Hurwitz dan titik endemik akan stabil jika tidak ada perubahan tanda pada $a_{0}, a_{1}, b_{1}, c_{1}, d_{1}, e_{1}$ dan $f_{1}$ Untuk itu, karena $a_{0}=1$ dan $a_{1}>0$ akan diperiksa apakah $b_{1}>0$. Mengingat $A B-$ 
$C N$ dengan $A N>0$, maka perlu diperiksa $A B-C N$ yang dinyatakan melalui polinom derajat lima dalam $\mu$ sebagai berikut :

$$
\begin{aligned}
A B-C N= & -\theta L \mu^{5}+(-\theta L b+2 A-\theta p \theta L+3 \theta L+B \theta L+b) \mu^{4}+(\theta p \theta L B+4 f+2 b f+2 \theta p \theta L+4 A b+3 b+ \\
& 6 \theta L b-\theta p \theta L b+\theta p+2 A f+b^{2}+2 \theta p f-3 \theta p b-3 \theta L B+2 b \theta L B-\theta L b^{2}-3 B+2 \theta L-4 A+9+ \\
& \left.A \theta p-2 \theta p^{2}\right) \mu^{3}+\left(2 f b^{2}+b f^{2}-5 b \theta L B+4 A f b+10 f+10 b-B-5 A+\theta p \theta L B b-\theta L+4 \theta p A b+\right. \\
& \theta L b f-A \theta p f-3 \theta p f b+\theta L b^{2}+B 2 \theta p \theta L b-4 f B+2 \theta p \theta L f+2 \theta L b-3 B b-A \theta L-B \theta p+B- \\
& 3 \theta L B+\theta p f+\theta p \theta L+2 A b^{2}-5 A f+4 b f-5 A b-2 \theta p b-4 A \theta p+2 \theta p f^{2}+3 \theta L b^{2}+2 \theta p^{2} A- \\
& \left.2 \theta p^{2} f\right) \mu^{2}+\left(b f^{2}-4 B b f-3 b \theta L B-2 A \theta p f^{2}+2 A b^{2} f-6 A f b-2 A \theta p \theta L f+4 \theta p A f b-2 \theta p \theta L B b\right. \\
& +b^{2}+f^{2}-2 \theta p \theta L A B-\theta L f B+B A b+B A \theta p+B A f-B \theta p f-A b \theta L-A \theta p \theta L-A \theta L f-\theta p A b- \\
& \left.\theta p \theta L B+\theta L b^{2} f-5 A \theta p f-3 \theta p f-2 \theta L b^{2} B\right) \mu+B A f b-\theta p \theta L B b-\theta p \theta L f b-f^{2} B b-\theta L f B b+ \\
& A \theta p f^{2}-A \theta p \theta L f-B b f \mp b \theta L B+B A \theta p f-5 A f b-A b^{2} f
\end{aligned}
$$

Mengingat koefisien suku $\mu^{5}$ adalah negatif maka akan diperiksa suku $\mu$ dalam derajat-derajat lainnya bernilai negatif yaitu :

\section{Pada suku $\mu^{4}$}

$$
-\theta L b+2 A-\theta p \theta L+3 \theta L+B \theta L+b=3 \theta L+B \theta L+b+2 A-(b+\theta p) \theta L
$$

Koefisien suku $\mu^{4}$ bernilai negatif bila

$$
\begin{aligned}
& (3+B) \theta L+2 A+b-(b+\theta p) \theta L \\
& b(1-\theta L)<\theta p \theta L-[(3+B) \theta L+2 A] \\
& b<\frac{\theta p \theta L-[(3+B) \theta L+2 A]}{(1-\theta L)}
\end{aligned}
$$

Pada suku $\mu^{3}$

$(\theta p(B+2)+2 b(3+B)+1) \theta L+(1+2 f+A) \theta p+2 f(2+b)+4 a+3+b) b+9-(\theta L b+\theta p(3 b+2 \theta p)) \theta+\left(\left(3 B+b^{2}\right) \theta L\right.$ $+3+4 A)$

Koefisien suku $\mu^{3}$ bernilai negatif bila

$(\theta p(B+2)+2 b(3+B)+1) \theta L+(1+2 f+A) \theta p+2 f(2+b)+4 a+3+b) b+9<(\theta L b+\theta p(3 b+2 \theta p)) \theta p+$

$\left(\left(3 B+b^{2}\right) \theta L+3+4 A\right)$

Pada suku $\mu^{2}$

$\left(\theta L B b+4 A b+f+\theta L+2 \theta L+2 \theta L f+2 f^{2}+2 \theta p A\right) \theta p+\left(b f+b^{2} B+2 b+3 b^{2}\right) \theta L+\left(2 b^{2}+b f+10+4 b\right) f+\left(B+2 b^{2}+\right.$ $4 f b) A+10 b-(5 b B+3 B+1+A) \theta L-(A f+3 f b+B+2 b+4 A+2 \theta p f) \theta p-(4 f+1+3 b) B-(5 f+5 b+5) A$

Koefisien suku $\mu^{2}$ bernilai negatif bila

$\left(\theta L B b+4 A b+f+\theta L+2 \theta L+2 \theta L f+2 f^{2}+2 \theta p A\right) \theta p+\left(b f+b^{2} B+2 b+3 b^{2}\right) \theta L+\left(2 b^{2}+b f+10+4 b\right) f+\left(B+2 b^{2}+\right.$ $4 f b) A+10 b<(5 b B+3 B+1+A) \theta L+(A f+3 f b+B+2 b+4 A+2 \theta p f) \theta p+(4 f+1+3 b) B+(5 f+5 b+5) A$

Pada suku $\mu$

$(4 A f b+B A) \theta p+\left(b f+2 A b^{2}+f+\theta L b^{2}\right) f+b^{2}+(A b+A \theta p+A f) B-\left(3 b B+f B+A b+A f+2 b^{2} B\right) \theta L-\left(2 A f^{2}+2 A \theta L f+\right.$ $2 \theta L B b+2 \theta L A B+B f+A \theta L+A b+\theta L B+5 A f+3 f b) \theta p-(4 B b+6 A b) f$

Koefisien suku $\mu$ bernilai negatif bila

$(4 A f b+B A) \theta p+\left(b f+2 A b^{2}+f+\theta L b^{2}\right) f+b^{2}+(A b+A \theta p+A f) B-\left(3 b B+f B+A b+A f+2 b^{2} B\right) \theta L<\left(2 A f^{2}+2 A \theta L f+\right.$

$2 \theta L B b+2 \theta L A B+B f+A \theta L+A b+\theta L B+5 A f+3 f b) \theta p+(4 B b+6 A b) f$

Pada suku $\mu$ derajat nol

$B A f b+b \theta L B+B A \theta p f-\theta p \theta L B b-\theta p \theta L f b-\theta L f B b-A \theta p f^{2}-f^{2} B b-A \theta p \theta L f-B b f-5 A f b-A b^{2} f$

Koefisien suku $\mu$ derajat nol bernilai negatif bila

$-(\theta L B+\theta p \theta L B) b<\left[(B A b+B A \theta p)-\left(\theta p \theta L b+\theta L B b+A \theta p f+f B b+A \theta p \theta L+B b+5 A b+A b^{2}\right)\right] f$

$b<\frac{\left[(B A b+B A \theta p)-\left(\theta p \theta L b+\theta L B b+A \theta p f+f B b+A \theta p \theta L+B b+5 A b+A b^{2}\right)\right] f}{-(\theta L B+\theta p \theta L B) b}$ 
Persamaan $(8-12)$ merupakan syarat bagi $b_{1}<0$, yang mengakibatkan kolom pertama Tabel Routh-Hurwitz mengalami perubahan tanda, sehingga dapat disimpulkan bahwa titik kritis $T_{2}$ tidak stabil.

\subsubsection{Simulasi Model}

a. Simulasi Model $\left(T_{1}\right)$

Model penyebaran Simulasi untuk titik kritis bebas penyakit dilakukan dengan menggunakan nilai awal $S_{p}(0)=119107, E_{p}(0)=0, I_{p}(0)=0, S_{l}(0)=122900, E_{L}(0)=0, I_{L}(0)=0$, dengan interval waktu selama 50bulan. Gambar 1 memperlihatkan bahwa tidak terdapatnya suatu penyakit disub populasi perempuan dan laki-laki dikarenakan tidak ada yang terinfeksi dan yang menginfeksi. Gambar tersebut memperlihatkan populasi perempuan dan laki-laki rentan yang seakan mengikat. Peningkatan populasi perempuan lebih tinggi dibanding populasi laki-laki, hal ini menunjukkan bahwa penyebaran penyakit sifilis lebih cepat terjadi pada kelompok populasi laki-laki.

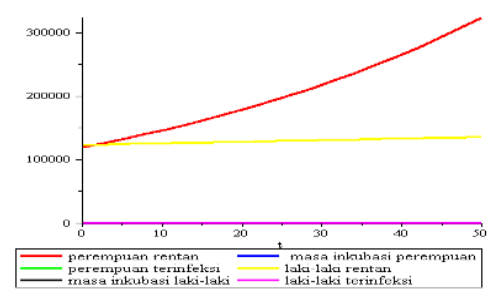

Gambar 1 : Kurva Simulasi Kondisi Bebas Penyakit

b. Simulasi Model $\left(T_{2}\right)$

Untuk titik kritis endemik diperoleh dengan menggunakan nilai awal $S_{p}(0)=119107, E_{p}(0)=70000, I_{p}(0)=30000, S_{l}(0)=122900, E_{L}(0)=70000, I_{L}(0)=53000$ dengan interval waktu selama 50 bulan. Gambar (2a) memperlihatkan bahwa jumlah populasi perempuan yang rentan mengalami penurunan, hal ini disebabkan karena adanya peluang terjadinya kontak antara perempuan yang rentan dan laki-laki yang terinfeksi sehingga sebagian populasi perempuan memasuki masa inkubasi, dan karena adanya kematian alami.Gambar (2b) memperlihatkan bahwa terjadi peningkatan sampai 75000 populasi perempuan disebabkan karena adanya laju perpindahan dari perempuan yang rentan memasuki masa inkubasi pada populasi perempuan. Penurunan drastis terjadi di bulan ke 5 karena adanya laju perpindahan populasi dari masa inkubasi ke populasi perempuan yang terinfeksi dan adanya kematian alami.pada Gambar (2c) memperlihatkan populasi perempuan yangterinfeksi terus mengalami kenaikan sejak bulan pertama disebabkan karena adanya laju perpindahan darimasa inkubasi ke populasi perempuan yang terinfeksi dan kenaikkan akan konvergen ke 250000 populasi perempuan yang terinfeksi karena adanya kematian alami. 


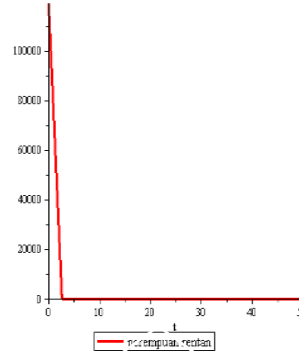

(a)

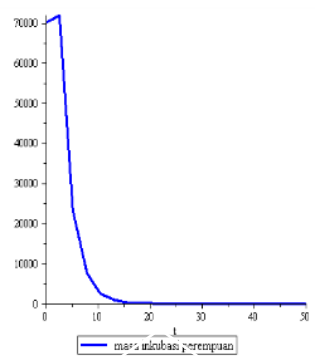

(b)

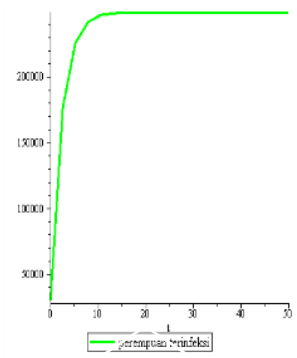

(c)

Gambar 2 : Kurya Simulasi Kondisi Endemik Pada Populasi Perempuan

Gambar 3(a) memperlihatkan jumlah populasi laki-laki yang rentan mengalami penurunan, hal ini disebabkan karena adanya peluang terjadinya kontak antara lakilaki yang rentan dan perempuan yang terinfeksi sehingga sebagian populasi laki-laki memasuki masa masa inkubasi, dan karena adanya kematian alami. Gambar 3(b) memperlihatkan jumlah populasi laki-laki mengalami penurunan di bulan ke 5 yang awalnya 80000 populasi menjadi 65000 populasi, kemudian mengalami penurunan lagi sampai bulan ke 10 disebabkan karena adanya laju perpindahan dari masa inkubasi ke populasi laki-laki yang terinfeksi dan adanya kematian alami, Gambar (3c) memperlihatkan jumlah populasi laki-laki terinfeksi terus mengalami kenaikan sejak bulan pertama disebabkan karena adanya laju perpindahan dari masa inkubasi ke populasi laki-laki yang terinfeksi kenaikan akan konvergen ke 390000 populasi laki-laki yang terinfeksi karena adanya kematian alami.

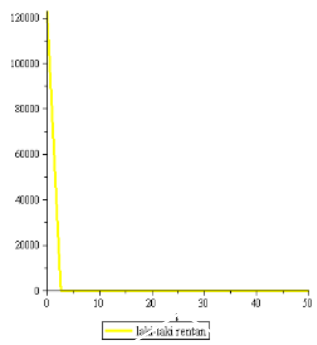

(a)

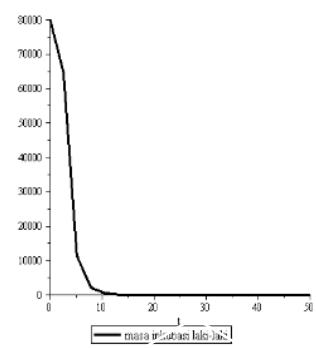

(b)

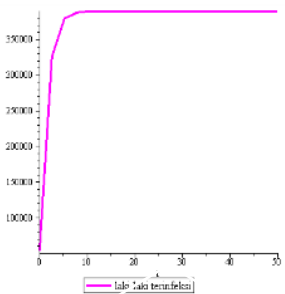

(c)

Gambar 3 : Kurva Simulasi Kondisi Erindemik Pada Populasi Laki-laki

Gambar 2(c) dan 3(c) memperlihatkan pula bahwa banyaknya populasi perempuan yang sembuh lebih sedikit dibandingkan dengan banyaknya populasi lakilaki yang sembuh. Hal ini menunjukkan bahwa pada kondisi endemik, penyebaran penyakit sifilis lebih cepat menyebar pada populasi perempuan. 


\section{KESIMPULAN}

Berdasarkan hasil dan pembahasan maka diperoleh model matematika penyebaran penyakit sifilis pada manusia, dua titik kritis yaitu titik kritis bebas penyakit yang stabil dan titik kritis endemikyang tidak stabil. Simulasi penyebaran penyakit sifilis pada suatu model SEI dalam penelitian ini menunjukkan fenomena bebas penyakit dan endemik. Hasil simulasi penyebaran penyakit sifilis menunjukkan bahwa pada kondisi bebas penyakit, populasi perempuan dan laki-laki mengalami peningkatan, dimana peningkatan jumlah populasi perempuan lebih tinggi dibanding populasi laki-laki. Hal ini menunjukkan penyebaran penyakit sifilis lebih cepat terjadi pada kelompok populasi laki-laki. Sebaliknya hasil simulasi keadaan endemik memperlihatkan bahwa penyebaran penyakit sifilis lebih cepat pada populasi perempuan.

\section{DAFTAR PUSTAKA}

[1] Ardyansyah, http://sifilis/425199436140-146\%20Ardiansyah.pdf, 2013, Diakses pada tanggal 5 Desember 2014, 4.

[2] Badan Pusat Statistik (BPS) Provinsi Sulawesi Tengah, Statistik Kependudukan Sulawesi Tengah, 2015, Palu, 1.

[3] Dinas Kesehatan Provinsi Sulawesi Tengah, Jumlah Kasus HIV,AIDS, dan Sifilis Menurut Jenis Kelamin, 2014, Palu, 1.

[3] Subiono, Sistem Linear dan Kontrol Optimal, Institut Teknologi Sepuluh Nopember, 2013, Surabaya, 115.

[4] Rafiqah Setiawaty, Analisis Kestabilan Pada Model Penyebaran Infeksi HIV di Kota Palu Dengan Matriks Jacobi, 2014, Universitas Tadulako Palu, 26.

[6] N, Bellomo dan I, Preziosi, Modelling Mathematical Methods And Scientific Computation,, CRC Press, Inc. Boca Raton, 1995, Florida, 67. 